\title{
PENGEMBANGAN KATALIS KALSIUM OKSIDA UNTUK SINTESIS BIODIESEL
}

\author{
Widdy Andya Fanny ${ }^{*}$, Subagjo1, Tirto Prakoso ${ }^{2}$ \\ ${ }^{1}$ Kelompok Keahlian Perancangan dan Pengembangan Proses Teknik Kimia \\ ${ }^{2}$ Kelompok Keahlian Energi dan Sistem Pemrosesan Teknik Kimia \\ Program Studi Teknik Kimia, Fakultas Teknologi Industri \\ Institut Teknologi Bandung \\ Jalan Ganesha 10 Bandung 40132 Indonesia \\ Email: subagjo@che.itb.ac.id
}

\begin{abstract}
Abstrak
Berkembangnya industri di dunia mengakibatkan meningkatnya kebutuhan akan bahan bakar. Selama ini bahan bakar yang digunakan diperoleh dari bahan bakar fosil yang jumlahnya terbatas, terlebih lagi hasil pembakaran bahan bakar fosil cenderung tidak ramah lingkungan. Untuk mengatasi berbagai kendala yang ditimbulkan dari penggunaan bahan bakar fosil, penelitian terhadap sumber energi alternatif mulai dilakukan. Biodiesel menarik perhatian dunia karena hasil pembakarannya lebih ramah lingkungan dan berasal dari sumber yang terbarukan. Biodiesel dihasilkan dari minyak nabati melalui reaksi transesterifikasi.Penelitian ini mengembangkan katalis $\mathrm{CaO}$ menjadi katalis $\mathrm{CaO}$ super basa untuk reaksi transesterifikasi pembentukan biodiesel. Aktivitas katalis $\mathrm{CaO}$ dan katalis $\mathrm{CaO}$ super basa duji tersebut diuji melalui reaksi transesterifikasi di dalam reaktor partaian pada suhu $60-65^{\circ} \mathrm{C}$ selama 4 jam. Karakterisasi padatan meliputi uji kristalinitas dengan metode XRD, uji kekuatan basa, dan uji luas permukaan dengan metode BET. Hasil penelitian menunjukkan bahwa padatan memiliki kekuatan basa berkisar 10-11, bersifat kristalin, dan memiliki luas permukaan sebesar 7,7 $\mathrm{m}^{2} / \mathrm{g}$ untuk $\mathrm{CaO}$ super basa dan 9,6 m²/g untuk CaO. Kadar metil ester biodiesel yang dihasilkan mencapai 98,8\%. Kadar metil ester menurut SNI (minimal 96,5 \%-b) dan ASTM, biodiesel dari reaksi ini dapat digunakan sebagai sumber energi terbarukan.
\end{abstract}

Kata Kunci : $\mathrm{CaO}, \mathrm{CaO}$ super basa, transesterifikasi, biodiesel

\begin{abstract}
The development of industrial's sector resulted in increasing demand for fuel. Fuel used is obtained from fossil fuel which is limited, and it produces several harmful gases to environment. To overcome these obstacles, the research on alternative energy resources has begun. Biodiesel has become more attractive because of its environmental benefits and it is made from renewable resources. Biodiesel is produced from vegetable oil by transesterification reaction. The aim of this research is development of $\mathrm{CaO}$ become super base $\mathrm{CaO}$ as heterogeneous for biodiesel synthesis by transesterification. The activities of both catalysts were tested by transesterification reaction in batch reactor at $60-65{ }^{\circ} \mathrm{C}$ for 4 hours. Both of those catalysts were characterized; include crystallinity by XRD, strength of base and surface area by BET method. Those solids have the basic strength about 10-11, crystalline structures, and the surface area of super base $\mathrm{CaO}$ about $7.7 \mathrm{~m}^{2} / \mathrm{g}$ and $\mathrm{CaO}$ about $9.6 \mathrm{~m}^{2} / \mathrm{g}$. The content of methyl ester in biodiesel produced reaches $98.8 \%$. According to SNI (minimal $96.5 \%$-wt) and ASTM, biodiesel of this reaction can be used as renewable energy source.
\end{abstract}

Keywords: $\mathrm{CaO}$, super base $\mathrm{CaO}$, transesterification, biodiesel

*korespondensi 


\section{Pendahuluan}

Berkembangnya industri di dunia saat ini mengakibatkan meningkatnya kebutuhan akan bahan bakar. Selama ini, bahan bakar yang digunakan diperoleh dari bahan bakar fosil yang jumlahnya terbatas, bukan sumber energi yang terbarukan, terlebih lagi hasil pembakaran dari bahan bakar fosil cenderung tidak ramah lingkungan. Oleh karena itu, dibutuhkan sumber energi alternatif yang terbarukan, lebih ramah lingkungan dan dapat memberikan solusi terhadap meningkatnya kebutuhan akan sumber energi.Kendala utama dari masalah lingkungan ini dapat dikurangi dengan mengganti bahan bakar fosil dengan bahan bakar nabati yang mudah diperbarui dan lebih ramah lingkungan. Terdapat beberapa macam bahan bakar nabati, tetapi yang paling umum digunakan pada bidang transportasi adalah biodiesel dan bioetanol.

Pada studi kali ini, biodiesel digunakan sebagai sumber alternatif. Biodiesel merupakan metil atau etil ester dari minyak nabati atau asam lemak. Beberapa peneliti telah melakukan studi dan penelitian terhadap minyak-minyak nabati sebagai sumber energi yang terbarukan, yang memiliki keunggulan antara lain dapat mengurangi emisi gas rumah kaca, $\mathrm{CH}_{4}, \mathrm{CO}$, dan $\mathrm{NO}_{\mathrm{x}}$.

Pada umumnya, sintesis biodiesel dilakukan melalui reaksi transesterifikasi menggunakan katalis basa cair $(\mathrm{NaOH}$ atau $\mathrm{KOH}$ ) dan enzim (lipase), dan melalui proses esterifikasi dengan menggunakan katalis asam cair $\left(\mathrm{H}_{2} \mathrm{SO}_{4}\right.$ atau $\left.\mathrm{H}_{3} \mathrm{PO}_{4}\right)$. Hasil konversi reaksi pembentukan biodiesel dengan menggunakan katalis basa cair dapat mencapai 98\%, bila menggunakan katalis asam cair dapat mencapai 99\%, dan penggunaan enzim lipase dapat menghasilkan konversi mencapai 91\% (Mittelbach dan Remschmidt, 2004). Kondisi operasi dengan menggunakan katalis basa dapat dilakukan pada tekanan atmosferik, dengan suhu kisaran $60-100{ }^{\circ} \mathrm{C}$. Kondisi operasi dengan menggunakan katalis asam homogen bisa dilakukan pada suhu $100{ }^{\circ} \mathrm{C}$, tekanan 5 bar. Sementara itu penggunaan dengan enzim harus dilakukan pada suhu $30-40{ }^{\circ} \mathrm{C}$ dan pH sekitar 7 (Kamini dan Iefuji, 2001). Persoalan utama yang dihadapi saat produksi biodiesel menggunakan katalis cair adalah proses pemurnian biodiesel dari campuran gliserol, katalis dan umpan yang tersisa agak sukar dilakukan karena katalis asam dan basa cair larut sempurna di dalam gliserol dan larut sebagian di dalam biodiesel. Hal ini berarti menambah satu unit pemisahan yang membutuhkan biaya yang tidak sedikit. Di samping itu, katalis cair untuk proses produksi biodiesel tidak dapat digunakan kembali, dan memerlukan perlakuan yang khusus agar tidak mencemari lingkungan (Singh dan Fernando, 2007). Untuk itulah perlu dikembangkan katalis padat untuk reaksi transesterifikasi yang lebih ramah lingkungan, lebih mudah dilakukan pemisahan dari sisa pengolahan biodiesel, dapat digunakan kembali, sehingga dapat menekan biaya produksi biodiesel (Mittelbach dan Remschmidt, 2004).

Banyak padatan yang bersifat basa yang telah diteliti sebagai katalis untuk produksi biodiesel, antara lain oksida-oksida dari logam-logam transisi, alkali, dan alkali tanah. Oksida logam-logam transisi cenderung bersifat asam, mahal, dan menghasilkan yield yang rendah. Berbeda dengan oksida logam alkali dan alkali tanah yang bersifat basa, murah, dan menghasilkan konversi yang tinggi (Mittelbach dan Remschmidt, 2004). Katalis basa heterogen umumnya berupa oksida logam dan logam oksida berpenyangga. Katalis heterogen oksida logam yang sering digunakan untuk reaksi transesterifikasi adalah $\mathrm{CaO}$ karena harganya murah, mudah didapat, dan tidak terlalu beracun (Lee dkk., 2009).

Penelitian awal terhadap oksida logam kalsium sebagai katalis untuk reaksi transesterifikasi telah menunjukan bahwa $\mathrm{CaO}$ juga memiliki aktivitas katalis yang sama tingginya dengan $\mathrm{K}_{2} \mathrm{O} / \mathrm{Al}_{2} \mathrm{O}_{3}$, tetapi senyawa $\mathrm{CaO}$ belum diuji stabilitasnya. Pada tahun 2006, Zhu dkk.melaporkan bahwa CaO super basa memiliki aktivitas yang lebih tinggi dibandingkan dengan CaO. Karena itu, CaO super basa sebagai katalis untuk reaksi pembentukan biodiesel menarik untuk dipelajari. Pada penelitian kali ini, pengembangan terhadap $\mathrm{CaO}$ sebagai katalis untuk reaksi transesterifikasi dan kinerja katalis tersebut dibandingkan untuk kondisi operasi yang telah dijalankan oleh penelitipeneliti sebelumnya dengan harapan konversi yang dihasilkan akan lebih tinggi daripada konversi yang telah dicapai oleh peneliti sebelumnya.

Secara umum, tujuan penelitian ini adalah mempelajari cara sintesis katalis $\mathrm{CaO}$ dan katalis $\mathrm{CaO}$ super basa, menguji aktivitas dan stabilitas keduanya dalam reaksi 
transesterifikasi, melakukan uji karakterisasi terhadap katalis-katalis tersebut, dan melakukan uji karakterisasi biodiesel yang dihasilkan dari reaksi transesterfikasi.

\section{Metodologi \\ 2.1 Bahan}

Bahan yang digunakan untuk sintesis katalis $\mathrm{CaO}$ adalah senyawa $\mathrm{CaCO}_{3}$. Bahan yang digunakan untuk sintesis katalis super basa oksida berbasis logam $\mathrm{Ca}$ adalah senyawa kalsium karbonat, dan larutan 0,12 $\mathrm{g} / \mathrm{mL}$ amonium karbonat.Uji kristalinitas tidak memerlukan bahan tambahan. Bahan yang digunakan untuk uji kekuatan basa katalis antara lain katalis hasil sintesis, metanol, indikator fenolftalein dan asam benzoat dalam pelarut $0,02 \mathrm{~mol} / \mathrm{L}$ larutan etanol pro analisis. Untuk tahap uji luas permukaan, bahan yang dibutuhkan antara lain gas nitrogen dan nitrogen cair. Untuk uji aktivitas katalis, bahan-bahan yang digunakan adalah metanol teknis dengan kemurnian 99,9\%, minyak sawit dan katalis hasil sintesis.

Untuk penentuan angka asam, bahanbahan yang dibutuhkan antara lain sampel biodiesel hasil sintesis, larutan KOH 0,1 N di dalam etanol $95 \%$-v, indikator fenolftalein, dan campuran pelarut 1:1 (v:v) dietileter/ etanol 95\%, atau 1:1 (v:v) toluen/etanol 95\%, atau 1:1 (v:v) toluen/isopropanol. Untuk penentuan angka sabun, bahan-bahan yang dibutuhkan antara lain sampel biodiesel hasil sintesis, larutan $\mathrm{KOH}$ dalam pelarut etanol $95 \%$-v, indikator fenolftalein, dan $\mathrm{HCl}$ $0,5 \mathrm{~N}$. Untuk tahap penentuan kadar gliserol total, bahan-bahan yang dibutuhkan adalah asam periodat (pro analisis), natrium tiosulfat (mutu reagen), kalium iodida (mutu reagen), asam asetat glasial (mutu reagen, 99,5 \%-b), larutan pati, kloroform (mutu reagen), kalium dikromat (mutu reagen, asam klorida mutu reagen, pekat, berat jenis 1,19), $\mathrm{KOH}$, etanol (mutu reagen, $95 \%$-v).

\subsection{Sintesis Katalis}

Proses sintesis $\mathrm{CaO}$ merujuk pada penelitian yang dilakukan oleh Kouzu dkk. (2008) dengan cara kalsinasi $\mathrm{CaCO}_{3}$ pada suhu $900 \quad{ }^{\circ} \mathrm{C}$ selama 1,5 jam. Untuk mendapatkan katalis $\mathrm{CaO}$ super basa, 12 gram $\mathrm{CaO}$ tersebut dicelupkan ke dalam larutan amonium karbonat berkonsentrasi $0,12 \mathrm{~g} / \mathrm{mL}$ sebanyak $171,5 \mathrm{~mL}$, diaduk selama 30 menit, dan disaring. Padatan yang terkumpul dipanaskan pada suhu $110{ }^{\circ} \mathrm{C}$, dan dikalsinasi pada suhu tinggi selama 1,5 jam. Setelah dikalsinasi, padatan $\mathrm{CaO}$ dibiarkan mencapai suhu $250{ }^{\circ} \mathrm{C}$ dan dimasukkan ke dalam desikator untuk mencegah terjadinya kontak antara permukaan katalis dengan uap air yang mengakibatkan menurunnya kekuatan basa katalis (Kouzu dkk., 2008).

\subsection{Karakterisasi Katalis}

Karakterisasi katalis yang dilakukan antara lain uji kristalinitas, uji kekuatan basa, dan uji luas permukaan. Kristalinitas ditentukan dengan difraksi sinar $\mathrm{X}$ menggunakan alat difraktometer PW1835 Based dengan tabung anoda $\mathrm{Cu}$ sebagai sumber sinarnya. Uji kristalinitas dilakukan di Laboratorium XRD Program Studi Teknik Metalurgi ITB.

Langkah uji kebasaan merujuk pada cara kerja Xie dkk.,pada tahun 2006. Uji kebasaan dilakukan dengan menggunakan metode indikator Hammet yang melibatkan titrasi dengan asam - basa. Indikator yang digunakan dalam percobaan ini adalah fenolftalein. Larutan asam yang digunakan pada percobaan ini adalah asam benzoat 0,02 mol/L dalam pelarut etanol kering. Padatan katalis dicelupkan di dalam $50 \mathrm{~mL}$ metanol, diaduk selama 1 jam, dan disaring. Filtrat yang diperoleh, ditetesi dengan indikator hingga berubah warna dan dititrasi dengan menggunakanasam benzoat dalam pelarut $0,02 \mathrm{~mol} / \mathrm{L}$ larutan etanol anhidrat. Ketika warna larutan menjadi bening, titrasi dihentikan.

Penentuan luas permukaan padatan dilakukan dengan metode BET (BrunauerEmmet-Teller) menggunakan alat NOVA 1000 Gas Sorption Analyzer. Penentuan luas permukaan padatan dilakukan di Laboratorium Instrumentasi dan Analisis Program Studi Teknik Kimia ITB.

\subsection{Uji Aktivitas Katalis}

Rangkaian alat terdiri dari reaktor gelas yang dilengkapi dengan pengaduk magnetik, kondensor, hot plate dan termometer. Bagian dalam reaktor juga dilengkapi saringan penyangga katalis. Setelah katalis ditempatkan di atas saringan tersebut, metanol dan minyak dimasukkan secara berurutan ke dalam reaktor gelas dan diaduk. Reaksi transesterifikasi dijalankan pada suhu reaksi antara 60 hingga $65{ }^{\circ} \mathrm{C}$ dengan mengatur kalor yang diberikan hot plate ke dalam reaktor. Dengan adanya pengadukan, campuran akan bersirkulasi 
secara kontinu dari batas atas campuran menembus unggun katalis hingga dasar reaktor gelas dan kembali menuju batas atas campuran melalui saluran gelas. Aliran kontinu ini diharapkan dapat menyebabkan terjadinya kontak antara reaktan dan katalis menjadi lebih baik.

\subsection{Karakterisasi Biodiesel}

Setiap sampel biodiesel diuji menggunakan metode titrasi iodometri-asam periodat. Hasil pengujian sampel tersebut berupa data angka asam, angka gliserol total, dan angka penyabunan. Parameter tersebut digunakan untuk mengetahui nilai konversi reaksi dan kadar metil ester dalam produk biodiesel.

\section{Hasil dan Pembahasan}

Pola XRD katalis $\mathrm{CaO}$ ditunjukkan Gambar 1 menampilkan difraktogram $\mathrm{CaO}$. Berdasarkan puncak-puncak yang terbentuk, kandungan utama permukaan padatan adalah $\mathrm{Ca}(\mathrm{OH})_{2}$ dan hanya sejumlah kecil CaO yang terbentuk. Adanya senyawa $\mathrm{Ca}(\mathrm{OH})_{2}$ diduga terbentuk akibat kontak antara permukaan padatan $\mathrm{CaO}$ dengan uap air dari udara bebas (Kouzu dkk., 2008).

Pola XRD katalis $\mathrm{CaO}$ super basa ditunjukkan Gambar 2. Berdasarkan difraktogram yang diperoleh, puncak karakteristik senyawa $\mathrm{CaO}$ tidak terdapat di dalam difraktogram yang ditunjukkan Gambar 2. Berdasarkan dari puncak-puncak yang terbentuk, kandungan utama permukaan padatan adalah $\mathrm{CaCO}_{3}$ dan

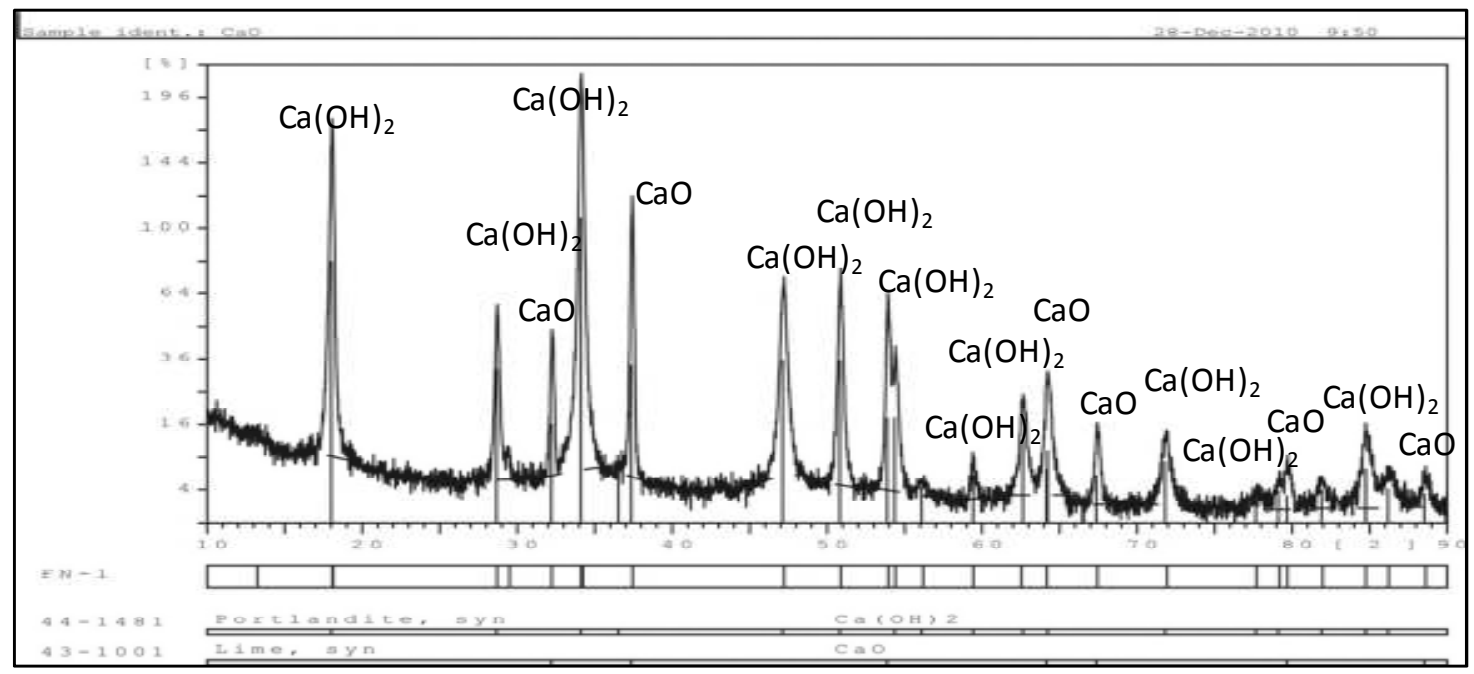

Gambar 1.Difraktogram CaO

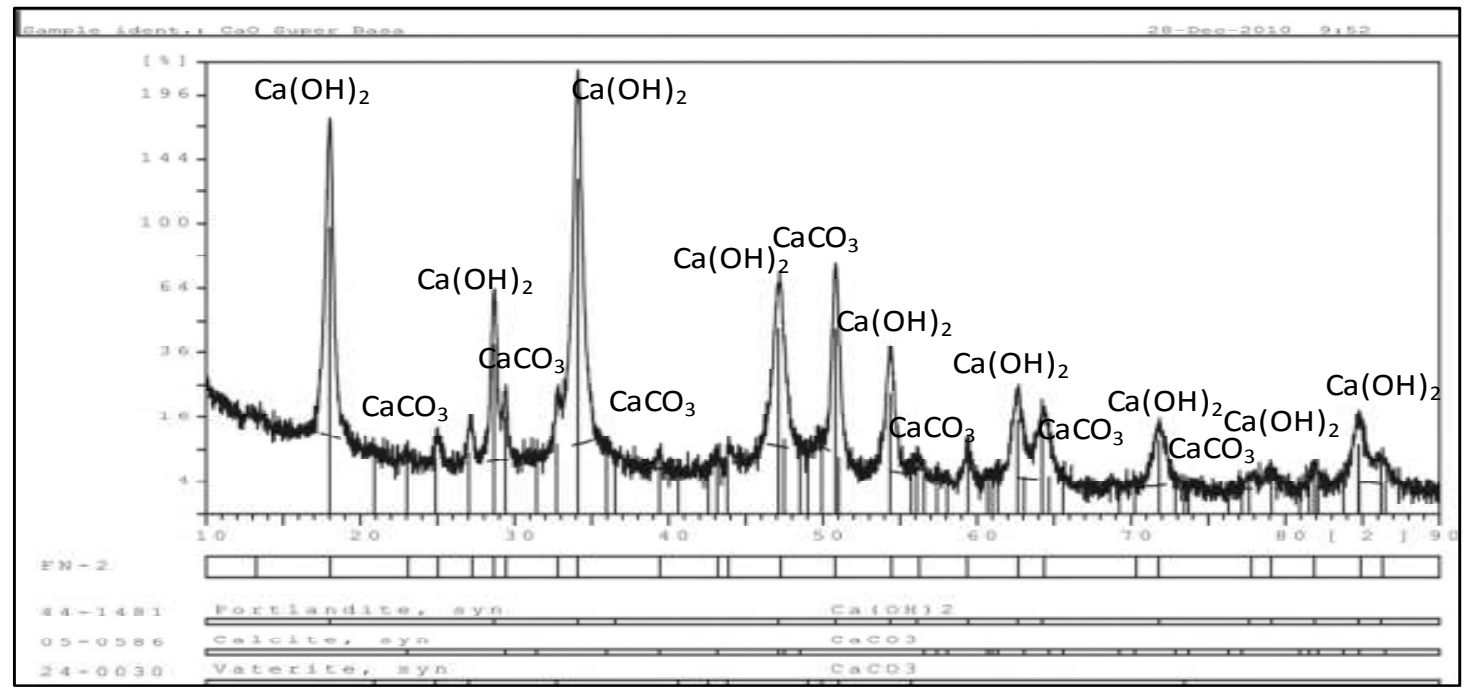

Gambar 2. Difraktogram CaO super basa 
$\mathrm{Ca}(\mathrm{OH})_{2}$. Dari Gambar 2, terdapat $\mathrm{CaCO}_{3}$ dalam 2 fasa, yaitu fasa vaterite (fasa metastabil) dan calcite (fasa stabil). Keberadaan puncak-puncak $\mathrm{CaCO}_{3}$ ini dapat disebabkan akibat tidak sempurnanya dekomposisi $\mathrm{CaCO}_{3}$ menjadi $\mathrm{CaO}$ dan $\mathrm{CO}_{2}$ sehingga membentuk $\mathrm{CaCO}_{3}$ dalam fasa calcite.

Kouzu melaporkan bahwa urutan kekuatan basa tertinggi ada pada $\mathrm{CaO}$, kemudian $\mathrm{Ca}(\mathrm{OH})_{2}$, dan yang terendah adalah $\mathrm{CaCO}_{3}$. Keberadaan senyawa $\mathrm{Ca}(\mathrm{OH})_{2}$ dan $\mathrm{CaCO}_{3}$ pada permukaan padatan $\mathrm{CaO}$ dan $\mathrm{CaO}$ super basa menyebabkan kekuatan basa pada permukaan padatan jadi menurun. Dari Gambar 1 dan Gambar 2 diketahui bahwa padatan $\mathrm{CaO}$ dan $\mathrm{CaO}$ super basa hasil sintesis memiliki puncak yang tajam dan sempit, yang mengindikasikan kedua padatan tersebut bersifat kristalin. Hasil uji kristatilintas memberikan efek terhadap uji kebasaan katalis $\mathrm{CaO}$ dan $\mathrm{CaO}$ super basa. Hal ini dapat dilihat dari Tabel 1 yang memaparkan hasil uji kekuatan basa katalis.

Tabel 1. Hasil Uji Kekuatan Basa Katalis

\begin{tabular}{lc}
\hline \multicolumn{1}{c}{ Senyawa } & Kekuatan Basa $\mathbf{H}_{-}$ \\
\hline CaO super basa & 11,45 \\
$\mathrm{CaO}$ & 10,97 \\
CaO super basa & \\
(Zhu dkk., 2006) & 26,5 \\
CaO (Kouzu dkk., & \\
2008 ) & $15,0-18,4$ \\
\hline
\end{tabular}

Hasil uji kekuatan basa yang diperoleh berbeda jauh dengan hasil yang terdapat pada literatur. Perbedaan tersebut dapat disebabkan karena adanya senyawa lain pada permukaan padatan $\mathrm{CaO}$ dan padatan $\mathrm{CaO}$ super basa. Dengan bahan baku $\mathrm{CaO}$ komersial, Zhu dkk. (2006) berhasil memperoleh katalis super basa $\mathrm{CaO}$ dengan kekuatan basa mencapai 26,5. Sedangkan Kouzu dkk. (2008) memperoleh kekuatan basa padatan $\mathrm{CaO}$ sekitar 15,0 - 18,4. Keberadaan senyawa $\mathrm{Ca}(\mathrm{OH})_{2}$ dan $\mathrm{CaCO}_{3}$ pada permukaan padatan $\mathrm{CaO}$ dan $\mathrm{CaO}$ super basa mengakibatkan turunnya kekuatan basa pada katalis $\mathrm{CaO}$ dan $\mathrm{CaO}$ super basa, seperti yang telah dilaporkan oleh Kouzu dkk. (2008).

Selain kekuatan basa katalis, luas permukaan katalis juga menentukan kinerja katalis dalam reaksi pembentukan biodiesel. Berikut merupakan hasil pengukuran luas permukaan padatan dengan menggunakan metode BET.

Tabel 2. Hasil Pengukuran Luas Permukaan

\begin{tabular}{lccc}
\hline CaO & $\begin{array}{c}\text { Pengukuran } \\
\mathbf{1}\end{array}$ & $\begin{array}{c}\text { Pengukuran } \\
\mathbf{2}\end{array}$ & $\begin{array}{c}\text { Rata- } \\
\text { rata }\end{array}$ \\
\hline $\begin{array}{l}\text { Super } \\
\text { basa }\end{array}$ & 7,3 & 8,0 & 7,7 \\
Basa & 10,8 & 8,3 & 9,6 \\
\hline
\end{tabular}

Dari hasil percobaan, diperoleh luas permukaan $\mathrm{CaO}$ super basa sekitar $9,6 \mathrm{~m}^{2} / \mathrm{g}$. Zhu dkk. pada tahun 2006 memperoleh luas permukaan padatan $\mathrm{CaO}$ super basa berkisar $6 \mathrm{~m}^{2} / \mathrm{g}$. Sementara itu, luas permukaan $\mathrm{CaO}$ hasil percobaan mencapai $7,7 \mathrm{~m}^{2} / \mathrm{g}$. Kouzu dkk. pada tahun 2008 memperoleh luas permukaan padatan $\mathrm{CaO}$ mencapai $13 \mathrm{~m}^{2} / \mathrm{g}$. Dengan kata lain, luas permukaan padatan $\mathrm{CaO}$ super basa hasil percobaan ini lebih tinggi dibandingkan dengan hasil yang diperoleh Zhu dkk. pada tahun 2006, dan luas permukaan $\mathrm{CaO}$ hasil percobaan ini tidak jauh berbeda jika dibandingkan dengan hasil yang diperoleh oleh Kouzu dkk. pada tahun 2008.

Sebelum pengujian di dalam reaksi transesterifikasi, masing-masing katalis direndam di dalam metanol teknis agar terbentuk spesi metoksi yang merupakan inisiator reaksi transesterifikasi. Mekanisme pembentukan gugus metoksi ditampilkan pada Gambar 3. Spesi metoksi yang terbentukmenyerang karbokation pada gugus karboksilat trigliserida sehingga membentuk senyawa antara alkoksikarbonil (Gambar 4). Perpindahan elektron akibat resonansi yang menyebabkan gugus karboksilat terlepas sebagai metil ester dan digliserida.

Reaksi transesterifikasi dengan mekanisme reaksi yang disajikan pada Gambar 4 dilangsungkan pada kondisi 60 $65{ }^{\circ} \mathrm{C}$ dan tekanan atmosferik selama 4 jam. Setelah 4 jam, diperoleh campuran produk reaksi yang membentuk 2 fasa di mana fasa metil ester menempati lapisan atas dan fasa

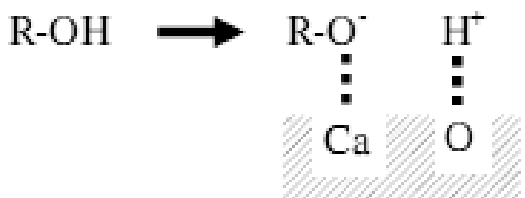

Gambar 3. Mekanisme pembentukan gugus metoksi (Kouzu dkk., 2008) 


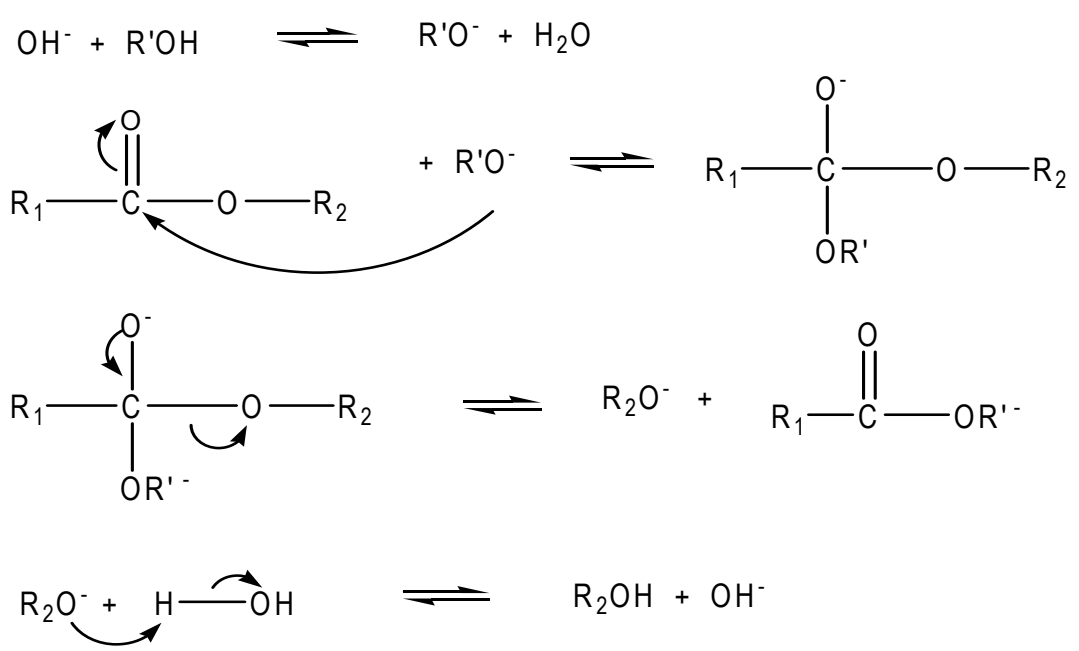

Gambar 4. Mekanisme reaksi transesterifikasi

gliserol menempati lapisan bawah. Untuk memisahkan katalis dari campuran reaksi, filtrasi merupakan cara pemisahan yang paling efektif untuk mencegah partikelpartikel padatan yang berukuran kecil terdispersi ke dalam campuran hasil reaksi sehingga campuran reaksi menjadi sangat basa. Setelah katalis terpisah, gliserol dipisahkan dari metil ester. Kemudian lapisan metil ester dicuci dengan air untuk menghilangkan sisa gliserol, metanol, dan katalis sampai pH metil ester mencapai 7.

Hasil uji kinerja katalis $\mathrm{CaO}$ dan $\mathrm{CaO}$ super basa dituliskan pada Tabel 3 dan Tabel 4. Secara keseluruhan, padatan $\mathrm{CaO}$ dan $\mathrm{CaO}$ super basa memiliki kinerja yang lebih baik sebagai katalis untuk reaksi pembentukan biodiesel. $\mathrm{CaO}$ menghasilkan konversi mencapai 99,89\% dan $\mathrm{CaO}$ super basa menghasilkan konversi mencapai 99,9\%. Pada penelitian ini, perbedaan kinerja kedua jenis padatan tersebut tidak terlalu signifikan karena kekuatan basa kedua jenis padatan tersebut tidak jauh berbeda.

Dibandingkan dengan hasil penelitian Jalil dan Pravitasati (2010), katalis CaO hasil percobaan ini memiliki aktivitas yang sama tinggi. Untuk itu, uji stabilitas CaO yang telah dilakukan oleh Jalil dan Pravitasari (2010) dapat dijadikan referensi uji stabilitas $\mathrm{CaO}$. Stabilitas katalis diuji dengan cara menggunakan kembali katalis yang telah digunakan pada reaksi transesterifikasi sebelumnya, dengan kondisi operasi yang sama. Jika kadar metil ester yang diperoleh rendah atau terbentuk sabun, maka uji stabilitas katalis dihentikan. Uji stabilitas katalis $\mathrm{CaO}$ dan $\mathrm{CaO}$ super basa dilakukan duplo yang hasilnya ditunjukkan pada Tabel 4.

Tabel 3. Data Aktivitas Katalis Cao dan Cao Super Basa

\begin{tabular}{ccc}
\hline Run & Katalis & \% konversi \\
\hline A & $\mathrm{CaO}$ & 99,89 \\
$\mathrm{~B}$ & $\mathrm{CaO}$ & 99,88 \\
$\mathrm{C}$ & $\mathrm{CaO}$ & 99,79 \\
$\mathrm{D}$ & $\mathrm{CaO}$ & 99,87 \\
5 & $\mathrm{CaO}$ Super Basa & 99,89 \\
6 & $\mathrm{CaO}$ & 99,90 \\
7 & CaO Super Basa & 99,88 \\
8 & CaO Super Basa & 99,92 \\
10 & CaO Super Basa & 99,91 \\
11 & CaO Super Basa & 99,91 \\
\hline
\end{tabular}

Keterangan

Run A-D dilakukan oleh Jalil dan Pravitasari (2010)

Memenuhi kriteria SNI

Seperti yang dituliskan pada Tabel 4, penggunaan ulang katalis $\mathrm{CaO}$ dan $\mathrm{CaO}$ super basa untuk kedua kalinya menghasilkan sabun. Karena itu, katalis $\mathrm{CaO}$ dan $\mathrm{CaO}$ super basa hanya dapat digunakan ulang sebanyak 1 kali. Dari uji stabilitas yang telah dilakukan, dapat disimpulkan bahwa pemakaian ulang katalis tidak menurunkan kadar metil ester yang diperoleh. Setelah reaksi pertama berakhir, katalis akan mengendap pada bagian bawah reaktor bersama lapisan gliserol. Agar dapat digunakan kembali, katalis harus dipisahkan dari campuran hasil reaksi. Terbawanya sejumlah kecil katalis dalam lapisan metil ester atau lapisan 


\begin{tabular}{|c|c|c|c|c|c|}
\hline \multicolumn{6}{|c|}{ Tabel 4. Hasil Karakterisasi Biodiesel } \\
\hline Run & Keterangan & $\begin{array}{l}\text { Angka } \\
\text { asam (mg- } \\
\mathrm{KOH} / \mathrm{g})\end{array}$ & $\begin{array}{l}\text { Angka } \\
\text { sabun (mg- } \\
\mathrm{KOH} / \mathrm{g} \text { ) }\end{array}$ & $\begin{array}{c}\text { Gliserol } \\
\text { total }(\%-b)\end{array}$ & $\begin{array}{c}\text { Kadar ester } \\
(\%-b)\end{array}$ \\
\hline A & - & 0,11 & 218,65 & 0,11 & 99,02 \\
\hline B & Reuse run A & 0,11 & 218,93 & 0,12 & 98,96 \\
\hline $\mathrm{C}$ & - & 0,02 & 221,75 & 0,21 & 98,26 \\
\hline $\mathrm{D}$ & Reuserun C & 0,11 & 221,06 & 0,13 & 98,85 \\
\hline 6 & $\begin{array}{l}\text { Katalis } \mathrm{CaO} \text { hasil sintesis pada } \\
\text { studi ini. Pemisahan dilakukan } \\
\text { dengan Filtrasi }\end{array}$ & 0,16 & 173,69 & 0,10 & 98,89 \\
\hline 7 & $\begin{array}{l}\text { Katalis CaO super basa (baru). } \\
\text { Pemisahan dilakukan dengan } \\
\text { filtrasi }\end{array}$ & 0,16 & 194,77 & 0,12 & 98,82 \\
\hline 8 & $\begin{array}{l}\text { Reuse dari Run 7. Pemisahan } \\
\text { dilakukan dengan filtrasi }\end{array}$ & 0,34 & 198,13 & 0,08 & 99,05 \\
\hline 9 & $\begin{array}{l}\text { Reuse dari Run } 8 \text {, produk } \\
\text { tersabunkan, analisa produk } \\
\text { tidak dapat dilakukan }\end{array}$ & - & - & - & - \\
\hline 10 & $\begin{array}{l}\text { Katalis } \mathrm{CaO} \text { super basa (baru). } \\
\text { Pemisahan dilakukan dengan } \\
\text { filtrasi }\end{array}$ & 0,15 & 183,58 & 0,09 & 98,98 \\
\hline 11 & $\begin{array}{l}\text { Reuse dari Run } 10, \text { pemisahan } \\
\text { dilakukan dengan filtrasi }\end{array}$ & 0,12 & 182,09 & 0,09 & 99,07 \\
\hline \multirow[t]{3}{*}{12} & $\begin{array}{l}\text { Reuse dari Run 11, produk } \\
\text { tersabunkan, analisa produk } \\
\text { tidak dapat dilakukan }\end{array}$ & - & - & - & - \\
\hline & SNI-04-7182-2006 & maks. 0,8 & $190-205$ & maks. 0,24 & $\min .96,5$ \\
\hline & ASTM 6751-02 & maks. 0,8 & $190-205$ & maks. 0,24 & - \\
\hline
\end{tabular}

\section{Keterangan:}

Run A-D dilakukan Jalil dan Pravitasari (2010) dengan katalis CaO

Berat katalis : $5 \%$-b minyak

MOR : Perbandingan metanol terhadap minyak (dalam mol $)=12$.

Memenuhi kriteria SNI

gliserol sering kali terjadi. Karenanya, asumsi ini dapat digunakan untuk perhitungan jumlah reaktan yang akan digunakan pada reaksi yang selanjutnya sehingga reaksi transesterifikasi tetap berlangsung dengan jumlah katalis yang sama.

Dari uji stabilitas, katalis $\mathrm{CaO}$ dan $\mathrm{CaO}$ super basa hanya dapat digunakan kembali sebanyak 1 kali pengulangan. Liu dkk., pada tahun 2008 melaporkan bahwa katalis $\mathrm{CaO}$ dapat digunakan hingga 20 kali pengulangan. Perbedaan yang terjadi dapat disebabkan adanya kemungkinan permukaan padatan $\mathrm{CaO}$ tidak lagi dapat menguraikan metanol menjadi ion metoksida sehingga reaksi transesterifikasi tidak dapat berlangsung dengan baik.

Hasil karakterisasi biodiesel telah dipaparkan pada Tabel 4. Dari hasil yang diperoleh, tiap-tiap biodiesel yang dihasilkan memiliki angka asam berkisar 0,1 hingga 0,33 mg-KOH/g. Menurut SNI dan ASTM, angka asam yang terdapat di dalam biodiesel hasil reaksi transesterifikasi tidak melampaui 
ambang batas. Tiap-tiap biodiesel yang dihasillkan memiliki angka sabun berkisar 173 hingga 199 mg-KOH/g. Beberapa sampel menunjukkan angka sabun yang lebih rendah daripada angka sabun biodiesel menurut SNI atau ASTM, namun tidak ada yang melampaui nilai batas atas menurut SNI atau ASTM.

Menurut SNI dan ASTM, batas atas jumlah \%-berat gliserol adalah 0,24. Tiaptiap sampel biodiesel yang dianalisis memiliki angka gliserol 0,08 hingga 0,12. Angka gliserol yang dimiliki tiap-tiap biodiesel tidak melampaui ambang batas yang ditetapkan oleh SNI dan ASTM.Tiap-tiap biodiesel yang dianalisa memiliki kadar ester 98 \%-b, melebihi persyaratan kadar ester menurut SNI, yaitu 96,5 \%-b. Maka, dari hasil analisa terhadap biodiesel yang dihasilkan melalui reaksi transesterifikasi, biodieselbiodiesel tersebut memenuhi syarat kelayakan menurut kriteria SNI dan ASTM.

\section{Kesimpulan}

Dari penelitian yang telah dilakukan, maka dapat diambil kesimpulan, antara lain kandungan utama pada padatan $\mathrm{CaO}$ hasil sintesis adalah $\mathrm{Ca}(\mathrm{OH})_{2}$ dan kandungan utama pada padatan $\mathrm{CaO}$ super basa adalah $\mathrm{Ca}(\mathrm{OH})_{2}$ dan $\mathrm{CaCO}_{3}$, dimana kedua padatan tersebut bersifat kristalin dengan masingmasing memiliki luas permukaan sebesar 7,7 dan 9,6 $\mathrm{m}^{2} / \mathrm{g}$. Kekuatan basa kedua padatan jauh lebih kecil daripada yang diharapkan (kekuatan basa masing-masing dari $\mathrm{CaO}$ dan $\mathrm{CaO}$ super basa diharapkan melebihi 15 dan 26), yaitu sebesar 10,97 untuk CaO dan 11,45 untuk $\mathrm{CaO}$ super basa. Padatan $\mathrm{CaO}$ dan $\mathrm{CaO}$ super basa memiliki aktivitas yang baik sebagai katalis untuk reaksi pembentukan biodiesel dengan konversi masing-masing mencapai 99,89\% dan 99,9\%, dan keduanya terdeaktivasi setelah 1 kali pemakaian ulang. Biodiesel yang dihasilkan dari percobaan ini memenuhi kriteria sesuai SNI dan ASTM, dimana SNI menetapkan kadar metil ester minimum sebesar 96,5 \%-b.

\section{Daftar Pustaka}

Jalil, E. R.; Pravitasari, A., Pengembangan Katalis Padat Untuk Sintesis Biodiesel, Tugas Akhir Sarjana, Institut Teknologi Bandung, Juli 2010.

Kamini, N. R.; Iefuji, H., Lipase catalyzed methanolysis of vegetable oils in aqueous medium by Cryptococcus spp. SP-2, Process Biochemistry, 2001, 37(4), 405 - 410.

Kouzu, M.; Kasuno, T.; Tajika M.; Sugimoto Y.; Yamanaka S.; Hidaka J., Calcium oxide as a solid base catalyst for transesterification of soybean oil and its application to biodiesel production, Fuel, 2008, 87(12), 2798 - 2806.

Lee, D.; Park, Y.; Lee, K., Heterogenous base catalysts for transesterification in biodiesel synthesis, Catalysis Surveys from Asia, 2009, 13(2), $63-77$.

Liu, X.; He, H.; Wang, Y.; Zhu, S.; Piao, X., Transesterification of soybean oil to biodiesel using $\mathrm{CaO}$ as a solid base catalyst, Fuel, 2008, 87(2), $216-221$.

Mittelbach, M.; Remschmidt, C., Biodiesel: The comprehensive Handbook, $2^{\text {nd }}$ edition, Graz, Austria, 2004.

Singh, A. K.; Fernando, S. D., Reaction kinetics of soybean oil transesterification using heterogenous metal oxide catalyst, Chemical Engineering and Technology, 2007, 30(12), 1716-1720.

Xie, W.; Peng, H.; Chen, L., Transesterification of soybean oil catalyzed by pottasium loaded on alumina as a solid-base catalyst, Applied Catalyst A: General, 2006, 300(1), 67-74.

Zhu, H.; Wu, Z.; Chen, Y.; Zhang, P.; Duan, S.; Liu, X.; Mao, Z., Preparation of biodiesel catalyzed by solid super base of calcium oxide and its refining process, Chinese Journal of Catalysis, 2006, 27(5), 391 - 39 